\title{
ORIGINAL RESEARCH \\ Absenteeism and Employer Costs Associated With Chronic Diseases and Health Risk Factors in the US Workforce
}

\author{
Garrett R. Beeler Asay, PhD; Kakoli Roy, PhD; Jason E. Lang, MPH, MS; \\ Rebecca L. Payne, MPH; David H. Howard, PhD
}

\begin{abstract}
Suggested citation for this article: Asay GRB, Roy K, Lang JE, Payne RL, Howard DH. Absenteeism and Employer Costs Associated With Chronic Diseases and Health Risk Factors in the US Workforce. Prev Chronic Dis 2016;13:150503. DOI: http:// dx.doi.org/10.5888/pcd13.150503.
\end{abstract}

\section{PEER REVIEWED}

\section{Abstract}

\section{Introduction}

Employers may incur costs related to absenteeism among employees who have chronic diseases or unhealthy behaviors. We examined the association between employee absenteeism and 5 conditions: 3 risk factors (smoking, physical inactivity, and obesity) and 2 chronic diseases (hypertension and diabetes).

\section{Methods}

We identified 5 chronic diseases or risk factors from 2 data sources: MarketScan Health Risk Assessment and the Medical Expenditure Panel Survey (MEPS). Absenteeism was measured as the number of workdays missed because of sickness or injury. We used zero-inflated Poisson regression to estimate excess absenteeism as the difference in the number of days missed from work by those who reported having a risk factor or chronic disease and those who did not. Covariates included demographics (eg, age, education, sex) and employment variables (eg, industry, union membership). We quantified absenteeism costs in 2011 and adjusted them to reflect growth in employment costs to 2015 dollars. Finally, we estimated absenteeism costs for a hypothetical small employer (100 employees) and a hypothetical large employer (1,000 employees).

\section{Results}

Absenteeism estimates ranged from 1 to 2 days per individual per year depending on the risk factor or chronic disease. Except for the physical inactivity and obesity estimates, disease- and riskfactor-specific estimates were similar in MEPS and MarketScan. Absenteeism increased with the number of risk factors or diseases reported. Nationally, each risk factor or disease was associated with annual absenteeism costs greater than $\$ 2$ billion. Absenteeism costs ranged from $\$ 16$ to $\$ 81$ (small employer) and $\$ 17$ to \$286 (large employer) per employee per year.

\section{Conclusion}

Absenteeism costs associated with chronic diseases and health risk factors can be substantial. Employers may incur these costs through lower productivity, and employees could incur costs through lower wages.

\section{Introduction}

Since the 1980s, the prevalence of chronic diseases and unhealthy lifestyle behaviors among American adults has increased. For instance, in 1980, the prevalence of hypertension was $24 \%$ and diabetes prevalence was below 3\%; however, by 2012 the prevalence of hypertension was $29 \%$ and diabetes $9 \%(1-3)$. In the US working population, one-third of adults are obese $(4,5)$, approximately 1 in 5 is a smoker (6), and more than half do not meet physical activity recommendations $(4,7)$. The Centers for Disease Control and Prevention recognizes obesity, tobacco use, and physical inactivity as "winnable battles." Winnable battles are public health priorities for which effective evidence-based interventions exist and could be broadly implemented to bring about large reductions in illness and death.

Employers are interested in reducing rates of chronic disease and reducing health risk factors because employers bear about $58 \%$ of total employee medical costs (8). Compared with their counter- 
parts, employees who have chronic diseases and unhealthy lifestyle behaviors have higher medical costs, miss more workdays, and are potentially less productive at work (9-12). The increasing age of the labor force may increase the prevalence of these conditions and their associated costs (13). In light of these considerations, many employers have adopted workplace wellness programs to improve health-related behaviors and reduce the incidence of chronic conditions (14).

Numerous studies have quantified the effect of diseases and risk factors on absenteeism (9-12,15-17). These studies often focused on a single condition and used various data sets, samples, and time periods, making it difficult to estimate the benefits of policies that affect multiple conditions simultaneously. Among studies that analyzed multiple conditions, some did not separately estimate absenteeism or account for other employee characteristics that may confound the relationship between chronic conditions and missed workdays.

The objective of this study was to estimate the association between absenteeism and 5 conditions: 3 risk factors (obesity, smoking, physical inactivity) and 2 chronic diseases (hypertension and diabetes). We applied the same method and regression framework to all conditions and analyzed absenteeism in 2 of the most commonly used data sources for health care costs - health risk appraisals (HRAs) from a large privately insured claims database (MarketScan) and a nationally representative health expenditure survey (the Medical Expenditure Panel Survey [MEPS]).

\section{Methods}

We analyzed absenteeism from 2008 through 2011 using samples of respondents who were aged 18 to 64 years, were continuously enrolled in the databases and employed for at least 1 year, were not pregnant, and responded to the question on missed workdays.

We analyzed data from the HRA subsample of the Truven Health MarketScan database. MarketScan is one of the largest commercial health care claims databases in the United States, representing more than 50 million employees and their dependents; the database is a de-identified convenience subpopulation of privately insured individuals (18). The HRA is a voluntary 3\%-to-5\% subsample of the MarketScan commercial claims data and contains self-reported information on health status (eg, hypertension) and health risk factors (eg, smoking). If a respondent completed more than 1 HRA in any year, we used the most recent HRA submitted.
MEPS is a publicly available, de-identified, annual survey consisting of a 2-year rolling panel design that collects data on the health care use and health status of respondents (19). The MEPS sample is representative of the civilian, noninstitutionalized US population. Our study used variables that were self-reported by respondents.

We measured absenteeism in MarketScan using responses to the question, "In the past 6 months how many days have you missed work due to illness or injury?" We annualized workdays missed by multiplying responses by 2 . In MEPS we measured absenteeism using responses to the question, "How many times [did you] miss more than a half-day of work since the last interview?" We annualized the missed workday variable by adjusting responses for the length of time respondents met the inclusion criteria.

We classified MarketScan respondents as physically inactive if they reported exercising fewer than 4 to 5 times per week with at least 30 minutes of moderate activity per period of exercise (20). We classified MEPS respondents as physically inactive if they responded no to the question asking if they "spend half an hour or more in moderate or vigorous physical activity at least three times a week." We classified respondents as obese if their body mass index (BMI in $\mathrm{kg} / \mathrm{m}^{2}$ ) was reported as 30 or higher. BMI was selfreported in MEPS; we calculated BMI from self-reported height and weight in MarketScan as ([weight in pounds $\times 703] /$ height in inches $^{2}$ ). We classified respondents as smokers if they responded affirmatively to the question, "Do you currently smoke?" MEPS respondents with diabetes and hypertension were identified according to responses to questions that asked them if they had "ever been told by a doctor or other health professional" that they had the disease. For MarketScan, respondents also self-reported hypertension or diabetes but did not distinguish between physician-diagnosed and self-diagnosed disease.

We adjusted for age categories (18-34, 35-49, 50-64 y), sex, educational attainment (no high school degree or GED [general educational development], high school degree, some college or college degree, or graduate degree), region (Northeast, Midwest, South, and or West), industry (11 classifications [Box]), and employment (full-time or part-time). MEPS data allowed for additional control factors: union membership (yes, no, inapplicable), race/ethnicity (non-Hispanic white, non-Hispanic black, Hispanic, Asian), occupation code of the employee (14 classifications [Box]), employer-paid sick leave (yes or no), and whether the respondent had private insurance (yes or no). We used an indicator for whether the respondent lived in a metropolitan statistical area (MSA) as a summary statistic to compare data sources but did not include MSA in regression analyses.

\footnotetext{
The opinions expressed by authors contributing to this journal do not necessarily reflect the opinions of the U.S. Department of Health and Human Services, the Public Health Service, the Centers for Disease Control and Prevention, or the authors' affiliated institutions.
} 


\section{Box. Industry Categories in MarketScan and Medical Expenditure Panel Survey}

\section{MarketScan}

Agriculture, forestry, fishing

Communications, utilities

Construction

Finance, insurance, real estate

Manufacturing, durable goods

Manufacturing, nondurable goods

Oil \& gas extraction, mining

Retail trade

Services

Transportation

Wholesale

Medical Expenditure Panel Survey

Agriculture

Construction

Financial services

Fishing

Forestry

Manufacturing

Mining

Other services

Professional services

Real estate

Retail trade

Transportation

Utilities

Wholesale trade

\section{Statistical analysis}

We analyzed both data sets using Stata 12.1 and estimated a zeroinflated Poisson regression model $(21,22)$ where the dependent variable was the number of self-reported workdays missed. The zero-inflated Poisson model accounts for additional zeroes in the dependent variable (missed workdays) by first fitting a logistic regression to predict the likelihood of an excess zero and then fitting a Poisson regression to obtain the count of missed workdays for nonexcess zeroes. We used the same set of explanatory variables as controls for both stages of the regression analysis. To estimate excess absenteeism or excess missed workdays, we used Stata's margins command to provide the predicted difference in missed workdays for those with and those without a risk factor or chronic disease. For the MarketScan data, we controlled for respondents who completed an HRA in more than 1 year with an indicator. We also included year indicators, clustered by respondent, and used robust standard errors in all regressions. All analyses us- ing MEPS data were weighted to produce estimates of the civilian, noninstitutionalized population meeting the sample inclusion criteria. Standard errors were adjusted for the MEPS's complex survey design.

We estimated 6 sets of regressions in 2 categories. First, we estimated the effect of each risk factor and chronic disease separately (smoking, obesity, physical inactivity, diabetes, and hypertension) while adjusting for different levels of controls (none, basic demographic, and full model). In doing so, we observed how estimates of absenteeism changed as we adjusted for additional factors. In the regressions, we adjusted for demographic variables (eg, age group, sex, and region), year of survey, work status indicators (eg, union membership, full-time status), and industry indicators (eg, industry type). In the second set of 3 regressions, we estimated risk factors and chronic diseases separately (ie, risk factors only and chronic diseases only). Finally, we estimated the association between the number of conditions, risk factors, chronic diseases, and total missed workdays.

To compute the base cost of absenteeism for the employed workforce, we multiplied the estimated number of excess missed workdays per year by daily compensation costs for an 8-hour workday. We calculated compensation costs using the Bureau of Labor Statistics average hourly compensation cost for US employers in 2011 (\$30.45) (23). We adjusted hourly employee compensation to 2015 dollars using the employment cost index (\$33.00) (24).

An employee's absence may reduce the productivity of coworkers, particularly when work relies on team production. To capture the team-based spillover effect of a missed workday, we multiplied absenteeism costs by $1.6(11,15,25)$. In an alternate scenario and to derive our lower-bound estimate on cost, we allowed for the scenario where an employee was able to make up work, or when work was completed by colleagues. In this scenario we multiplied costs by 0.43 (26). Using these 2 scenarios, the lower- and upperbound range for the cost of a 1-hour absence would be $\$ 14.19$ and $\$ 52.81$ (in 2015 dollars).

To obtain condition-specific absenteeism costs, we multiplied the cost per person per year by the prevalence of the condition. When computing national costs, we used the MEPS prevalence and absenteeism estimates and multiplied them by the total employed population in the United States in 2011: 139 million people (27).

To estimate costs for employers, we assumed a small employer had 100 employees and a large employer had 1,000 employees. Because MEPS is a nationally representative survey, we used the MEPS data to extrapolate costs for small employers. We used MarketScan estimates to extrapolate costs for large employers.

The opinions expressed by authors contributing to this journal do not necessarily reflect the opinions of the U.S. Department of Health and Human Services, the Public Health Service, the Centers for Disease Control and Prevention, or the authors' affiliated institutions. 
MarketScan HRA and MEPS are de-identified data sets; our research did not involve human subjects (defined by Title 45 Code of Federal Regulations, Part 46). Therefore, approval from an institutional review board was not required.

\section{Results}

In MarketScan, 356,758 observations met our inclusion criteria (Table 1). Of these, 127,143 individuals filled out an HRA in more than 1 year; thus, the 356,758 observations came from 229,615 individuals. The prevalence rates of the 5 conditions studied in the MarketScan sample were 27.4\% for current smoking, 55.9\% for physical inactivity, $26.0 \%$ for obesity, $18.0 \%$ for hypertension, and $4.8 \%$ for diabetes. In the MEPS analysis, 24,006 individuals met inclusion criteria. The MEPS prevalence rates were $17.2 \%$ for current smoking, $39.7 \%$ for physical inactivity, $30.0 \%$ for obesity, $24.9 \%$ for hypertension, and $6.0 \%$ for diabetes. The average number of missed workdays was 2.2 days per year for all employees in the MarketScan sample and 2.8 days per year for all employees in the MEPS sample. In MarketScan, 200,665 (56.2\%) respondents and in MEPS 12,498 (52.1\%) respondents reported zero absenteeism days.

MEPS and MarketScan estimates of the number of regression-adjusted excess missed workdays in the full model were qualitatively similar to each other, although the point estimates were different (Figure 1 and Table 2). MarketScan captures data on a more homogenous and potentially more economically advantaged population than does MEPS. Hence, it was not surprising that the results between the 2 data sets diverged slightly. However, as we adjusted for additional covariates the estimates for each data set became closer to each other in magnitude. Differences between the 2 data sets remained for estimates of physical inactivity and obesity.

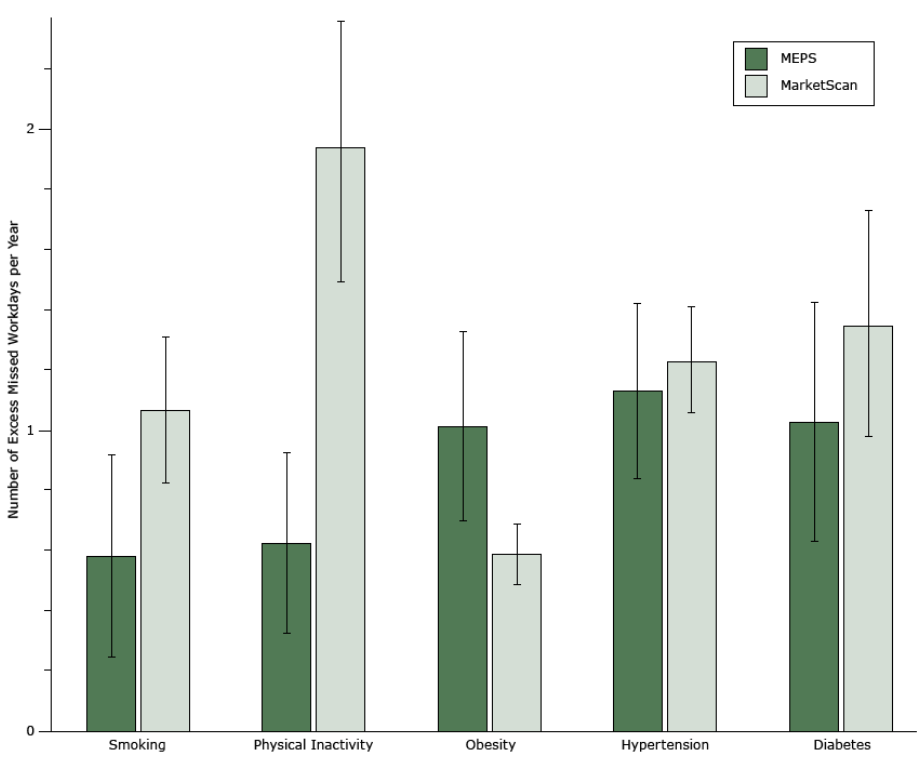

Figure 1. Regression-adjusted number of excess missed workdays per year by chronic disease or risk factor from the full model, which controlled for industry and employee characteristics. Error bars indicate 95\% confidence intervals. Abbreviation: MEPS, Medical Expenditure Panel Survey.

Individuals with a condition had significantly greater absenteeism than those without one. For example, using MarketScan we estimated that a smoker will miss 1.07 (95\% confidence interval [CI], $0.83-1.31$ ) more workdays than a nonsmoker. Across all conditions, as we adjusted for additional covariates, the estimated magnitude of excess missed workdays decreased (Table 2). When we examined individuals with multiple risk factors or diseases, the effect of any 1 condition remained significant after we adjusted for other factors. Similarly, adding risk factors and chronic diseases in the same regression changed the magnitude of the coefficients, but significance and coefficient sign remained the same.

We found a correlation between the number of conditions an employee reported and the predicted total number of missed workdays per year (Figure 2). Employees with 0 or 1 condition missed 2.0 workdays (MarketScan) or 2.3 workdays (MEPS). Employees with 2 or 3 conditions missed 4.5 days (MarketScan) or 3.7 days (MEPS). Finally, individuals with 4 or 5 conditions missed 8.6 days (MarketScan) or 4.4 days (MEPS). We found a similar pattern for number of risk factors or chronic diseases.

\footnotetext{
The opinions expressed by authors contributing to this journal do not necessarily reflect the opinions of the U.S. Department of Health and Human Services, the Public Health Service, the Centers for Disease Control and Prevention, or the authors' affiliated institutions.
} 


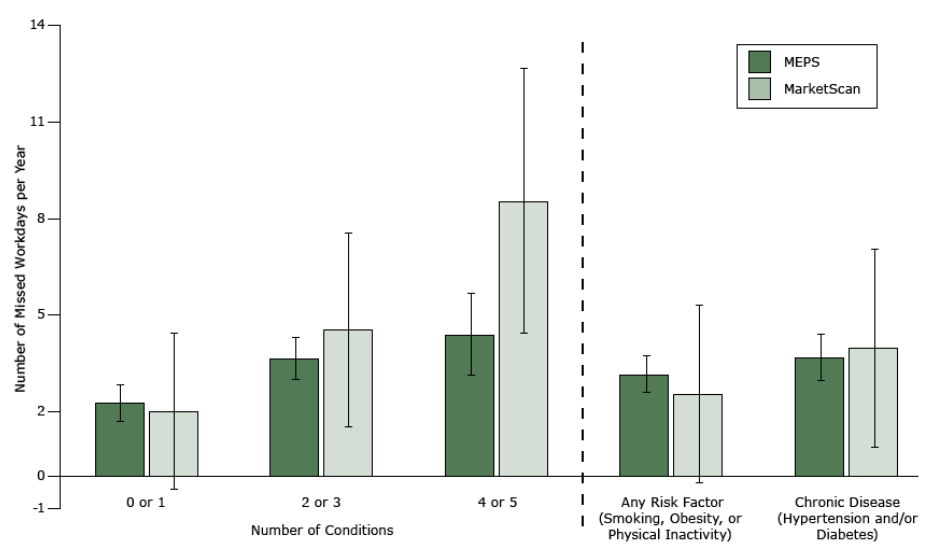

Figure 2. Regression-adjusted number of missed workdays per year. Error bars indicate 95\% confidence intervals. Abbreviation: MEPS, Medical Expenditure Panel Survey.

When we used our regression results to calculate the total cost of absenteeism to employers, we found that obesity had the highest total cost at $\$ 11.2$ billion per year (Table 3). After obesity, total costs for each condition were ranked as follows: hypertension ( $\$ 10.3$ billion), physical inactivity ( $\$ 9.1$ billion), current smoking ( $\$ 3.6$ billion), and diabetes ( $\$ 2.2$ billion). In our sensitivity analyses, lower and upper estimates for costs ranged between $\$ 0.9$ billion (diabetes) and $\$ 17.9$ billion (obesity).

Extrapolating these results to reflect employer size, we found that per-year absenteeism for a small employer ranged from 6 days for diabetes to 31 days for obesity and costs ranged from $\$ 1,621$ for diabetes to $\$ 8,065$ for obesity (Table 4$)$. A large employer $(1,000$ employees) could face absenteeism rates of 65 days for diabetes to 1,083 days for physically inactive employees. Annual costs for a large employer could range from approximately $\$ 17,000$ for diabetes to more than $\$ 285,000$ for physical inactivity.

\section{Discussion}

We estimated that absenteeism costs associated with each of the 5 conditions - hypertension, diabetes, smoking, physical inactivity, and obesity - were greater than $\$ 2$ billion per condition per year. Accounting for costs imposed by absenteeism will be useful in assessing the impact of programs and policies that affect the prevalence of these conditions. We cannot determine from these data whether employers bear this cost through lower profits or employees bear the cost through lower wages.

After adjusting for wage growth to 2015, our estimates of absenteeism costs were similar to previous estimates: for instance, for obesity, our estimated cost of \$11.2 billion (range, \$4.8-\$17.9 billion) was within the range of prior estimates: $\$ 4.3$ billion in 2004 ( $\$ 5.5$ billion in 2015 dollars) and $\$ 12.8$ billion in 2008 (\$14.6 bil- lion in 2015 dollars) (10,28). Regarding the magnitude of excess workdays missed, our estimate for smoking of about 1 day was smaller than reported previously (2.3-2.6 days) $(12,16)$. However, when we added a control for former smokers, our MarketScan absenteeism estimate increased to 2.2 days. (MEPS did not report whether respondents were former smokers.)

Our absenteeism estimates for diabetes, 1 to 2 days, were smaller than estimates of previous studies (3 days) (9). Likewise, our physical inactivity estimates (1-2 days) were smaller than previous estimates (4 days) (17). Differences between our estimates and prior estimates may be attributable to our more recent study period and our inclusion of additional controls, which tend to reduce the number of missed workdays attributable to risk factors or diseases.

Our study has several limitations. First, health-related conditions (smoking, physical inactivity, obesity) are primary risk factors for chronic diseases such as hypertension and diabetes. We did not model the disease pathway or the potential interaction of health risk factors and chronic diseases; prior research has the same limitation. In addition, because we were not able to control for former smokers in the MEPS sample, we underestimated the number of missed workdays associated with smoking. Second, our employerspecific estimates were extrapolations; we did not have actual employer size as a variable in the data set. Third, we did not account for the relationship between the labor market (eg, employment and wages) and disease status. One potential labor market outcome could be that people with chronic conditions have lower-paying jobs. However, recent research found no difference in wages after controlling for health insurance costs (29). Fourth, our data did not allow us to distinguish between type 1 and type 2 diabetes; nevertheless, most (>95\%) Americans who report having diabetes have type 2 diabetics, and our data probably reflects this proportion (30). Fifth, the MarketScan data are not nationally representative; however, MarketScan commercial encounters data in 2011 had more than 52 million enrollees (employees and dependents) and the database is projectable to $58 \%$ of the US population. The HRA sample is a voluntary subset of employees, and respondents may differ from the larger pool of MarketScan individuals in ways that reduce the generalizability of results.

This is the first study to examine absenteeism associated with multiple risk factors and chronic diseases using MarketScan and MEPS. We found the estimates of absenteeism to be similar for the 2 data sets, except for physical inactivity and obesity. The substantial difference in physical inactivity estimates may reflect differences between MarketScan and MEPS in how the question on physical activity was worded. We find robust evidence that risk factors and chronic diseases are strongly associated with increased employee absenteeism.

The opinions expressed by authors contributing to this journal do not necessarily reflect the opinions of the U.S. Department of Health and Human Services, the Public Health Service, the Centers for Disease Control and Prevention, or the authors' affiliated institutions. 
Workplace wellness programs have potential to reduce both medical and absenteeism costs (31). Although such programs, their comprehensiveness, and their potential returns vary, workplace programs are important partners in improving health. As an example, the American Heart Association reiterated in 2015 its commitment to workplace wellness as a way of improving cardiovascular health (14). While improving employee health and reducing absenteeism initially benefit employers and employees, a healthy workforce and an increase in productivity are national resources with benefits that extend beyond private sector employers and their employees.

\section{Acknowledgments}

We thank 2 anonymous reviewers for their comments on previous versions of this manuscript. David Howard was supported by Centers for Disease Control and Prevention Intergovernmental Personnel Act 1600867 for this work. The findings and conclusions in this report are those of the authors and do not necessarily represent the views of the Centers for Disease Control and Prevention. The authors report no conflicts of interest relevant to this article.

\section{Author Information}

Corresponding Author: Garrett R. Beeler Asay, PhD, Office of the Associate Director for Policy, Centers for Disease Control and Prevention, 1600 Clifton Rd, MS D-28, Atlanta, Georgia 30333. Telephone: 404-639-6188. Email: hrp9@cdc.gov.

Author Affiliations: Kakoli Roy, Rebecca L. Payne, Office of the Associate Director for Policy, Centers for Disease Control and Prevention, Atlanta, Georgia; Jason E. Lang, National Center for Chronic Disease Prevention and Health Promotion, Centers for Disease Control and Prevention, Atlanta, Georgia; David H. Howard, Rollins School of Public Health, Emory University, Atlanta, Georgia.

\section{References}

1. Egan BM, Zhao Y, Axon RN. US trends in prevalence, awareness, treatment, and control of hypertension, 1988-2008. JAMA 2010;303(20):2043-50.

2. Nwankwo T, Yoon SS, Burt V, Gu Q. Hypertension among adults in the United States: National Health and Nutrition Examination Survey, 2011-2012. NCHS Data Brief 2013; (133):1-8.

3. American Diabetes Association. National diabetes statistics report, 2014. http://www.diabetes.org/diabetes-basics/statistics/ . Accessed June 25, 2015.
4. Ogden CL, Carroll MD, Kit BK, Flegal KM. Prevalence of obesity among adults: United States, 2011-2012. NCHS data brief, no. 131. Hyattsville (MD): National Center for Health Statistics; 2013.

5. Flegal KM, Carroll MD, Ogden CL, Curtin LR. Prevalence and trends in obesity among US adults, 1999-2008. JAMA 2010; 303(3):235-41.

6. Centers for Disease Control and Prevention. Current cigarette smoking prevalence among working adults - United States, 2004-2010. MMWR Morb Mortal Wkly Rep 2011; 60(38):1305-9.

7. Centers for Disease Control and Prevention. Adult participation in aerobic and muscle-strengthening physical activities — United States, 2011. MMWR Morb Mortal Wkly Rep 2013;62(17):326-30.

8. Girod CS, Weltz SA, Heart SK. 2015Milliman Medical Index. Online report. 2015. http://www.milliman.com/insight/ Periodicals/mmi/2015-Milliman-Medical-Index/. Accessed August 22, 2016.

9. American Diabetes Association. Economic costs of diabetes in the U.S. in 2012. Diabetes Care 2013;36(4):1033-46.

10. Finkelstein EA, DiBonaventura M, Burgess SM, Hale BC. The costs of obesity in the workplace. J Occup Environ Med 2010; 52(10):971-6.

11. Mitchell RJ, Bates P. Measuring health-related productivity loss. Popul Health Manag 2011;14(2):93-8.

12. Bunn WB 3d, Stave GM, Downs KE, Alvir JMJ, Dirani R. Effect of smoking status on productivity loss. J Occup Environ Med 2006;48(10):1099-108.

13. US Department of Labor, Bureau of Labor Statistics. Labor force projections to 2024: the labor force is growing, but slowly. 2015. http://www.bls.gov/opub/mlr/2015/article/laborforce-projections-to-2024-1.htm. Accessed August 22, 2016.

14. Fonarow GC, Calitz C, Arena R, Baase C, Isaac FW, LloydJones D, et al.. Workplace wellness recognition for optimizing workplace health: a presidential advisory from the American Heart Association. Circulation 2015;131(20):e480-97.

15. Goetzel RZ, Long SR, Ozminkowski RJ, Hawkins K, Wang S, Lynch W. Health, absence, disability, and presenteeism cost estimates of certain physical and mental health conditions affecting U.S. employers. J Occup Environ Med 2004; 46(4):398-412.

16. Tsai SP, Wendt JK, Cardarelli KM, Fraser AE. A mortality and morbidity study of refinery and petrochemical employees in Louisiana. Occup Environ Med 2003;60(9):627-33.

17. van Amelsvoort LGPM, Spigt MG, Swaen GMH, Kant I. Leisure time physical activity and sickness absenteeism; a prospective study. Occup Med (Lond) 2006;56(3):210-2.

\footnotetext{
The opinions expressed by authors contributing to this journal do not necessarily reflect the opinions of the U.S. Department of Health and Human Services, the Public Health Service, the Centers for Disease Control and Prevention, or the authors' affiliated institutions.
} 
18. Marketscan Research. Truven Health Analytics. https:// marketscan.truvenhealth.com/marketscanportal/portal.aspx. Accessed August 25, 2016.

19. Medical Expenditure Panel Survey-Household Component sample design and collection process. Rockville (MD): Agency for Healthcare Research and Quality. http:// www.meps.ahrq.gov/survey_comp/hc_data collection.jsp.Accessed August 22, 2016.

20. US Department of Health and Human Services. Physical activity guidelines for Americans. 2008. https://health.gov/ paguidelines/guidelines/. Accessed August 22, 2016.

21. StataCorp. Stata statistical software: release 12. College Station (TX): StataCorp LP; 2011.

22. Greene WH. Econometric analysis, 7th edition. Upper Saddle River (NJ): Prentice Hall; 2000.

23. Bureau of Labor Statistics. Employer costs for employee compensation news release, December 2011. Released March 2012. http://www.bls.gov/news.release/archives/ecec 03142012.htm. Accessed August 22, 2016.

24. Bureau of Labor Statistics. Employment cost index: historical listing - volume IV. National Compensation Survey, July 2016. http://www.bls.gov/web/eci/ecconstnaics.pdf. Accessed August 22, 2016.

25. Nicholson S, Pauly MV, Polsky D, Sharda C, Szrek H, Berger ML. Measuring the effects of work loss on productivity with team production. Health Econ 2006;15(2):111-23.

26. Krol M, Brouwer WB, Severens JL, Kaper J, Evers SM. Productivity cost calculations in health economic evaluations: correcting for compensation mechanisms and multiplier effects. Soc Sci Med 2012;75(11):1981-8.

27. Bureau of Labor Statistics. Data retrieval: labor force statistics from the current population survey: table A-1. Employment status of the civilian population by sex, and age. http:// www.bls.gov/webapps/legacy/cpsatab1.htm. Accessed August 22, 2016.

28. Cawley J, Rizzo JA, Haas K. Occupation-specific absenteeism costs associated with obesity and morbid obesity. J Occup Environ Med 2007;49(12):1317-24.

29. Bhattacharya J, Bundorf MK. The incidence of the healthcare costs of obesity. J Health Econ 2009;28(3):649-58.

30. Centers for Disease Control and Prevention. National diabetes fact sheet, 2011:fast facts on diabetes. http://www.cdc.gov/ diabetes/pubs/pdf/ndfs_2011.pdf. Accessed August 22, 2016.

31. Baicker K, Cutler D, Song Z. Workplace wellness programs can generate savings. Health Aff (Millwood) 2010; 29(2):304-11.

\footnotetext{
The opinions expressed by authors contributing to this journal do not necessarily reflect the opinions of the U.S. Department of Health and Human Services, the Public Health Service, the Centers for Disease Control and Prevention, or the authors' affiliated institutions.
} 


\section{Tables}

Table 1. Summary Statistics on US Workforce: Data From MarketScan ${ }^{a}$ and Medical Expenditure Panel Survey, 2008-2011 ${ }^{\text {b, c }}$

\begin{tabular}{|c|c|c|}
\hline Variable & MarketScan (No. of Observations $=356,758^{d}$ ) & $\begin{array}{l}\text { Medical Expenditure Panel Survey }(\mathrm{N}= \\
24,006)\end{array}$ \\
\hline Self-reported workdays missed, $n$ (SD) & $2.2(12.6)$ & $2.8(8.7)$ \\
\hline Female & $129,503(36.3)$ & $10,075(42.0)$ \\
\hline \multicolumn{3}{|l|}{ Age group, $y$} \\
\hline $18-34$ & $93,064(26.1)$ & $7,344(30.6)$ \\
\hline $35-49$ & $154,766(43.4)$ & $9,435(39.3)$ \\
\hline $50-64$ & $108,928(30.5)$ & $7,227(30.1)$ \\
\hline Current smoking ${ }^{e}$ & $60,477(27.4)$ & $4,122(17.2)$ \\
\hline Former smoking & $12,126(23.7)$ & NA \\
\hline Physical inactivity ${ }^{e}$ & $28,568(55.9)$ & $9,539(39.7)$ \\
\hline Obesity & $92,910(26.0)$ & $7,190(30.0)$ \\
\hline Hypertension ${ }^{e}$ & $35,750(18.0)$ & $5,972(24.9)$ \\
\hline Diabetes $^{e}$ & $7,361(4.8)$ & $1,431(6.0)$ \\
\hline \multicolumn{3}{|l|}{ Education $^{\mathrm{e}}$} \\
\hline No high school degree or GED & $776(0.4)$ & $2,752(11.5)$ \\
\hline High school degree & $11,740(6.1)$ & $10,229(42.6)$ \\
\hline Some college/college degree & $178,120(91.8)$ & $5,654(23.6)$ \\
\hline Graduate degree & $3,316(1.7)$ & $5,371(22.4)$ \\
\hline Metropolitan statistical area & $341,029(95.6)$ & $20,470(85.3)$ \\
\hline \multicolumn{3}{|l|}{ Region $^{f}$} \\
\hline Northeast & $104,504(29.3)$ & $4,308(17.9)$ \\
\hline Midwest $^{\mathrm{g}}$ & $38,541(10.8)$ & $5,368(22.4)$ \\
\hline South & $118,979(33.4)$ & $8,954(37.3)$ \\
\hline West & $94,563(26.5)$ & $5,376(22.4)$ \\
\hline Part-time employee $^{h}$ & $3,157(0.9)$ & NA \\
\hline Employer offers paid sick leave ${ }^{i}$ & $\mathrm{NA}$ & $15,753(65.6)$ \\
\hline Union membership & $30,3(8.5)$ & $2,886(12.0)$ \\
\hline Private insurance ${ }^{i}$ & NA & $20,389(84.9)$ \\
\hline
\end{tabular}

Abbreviations: GED, general educational development; NA, not applicable.

${ }^{a}$ MarketScan is a large US commercial health care claims database; it is a de-identified convenience subpopulation of privately insured individuals (18).

${ }^{\mathrm{b}}$ All values are number (percentage) unless otherwise indicated. Percentages may not total 100 because of rounding.

${ }^{\mathrm{c}}$ All values are self-reported.

${ }^{d}$ The 356,758 observations were of 229,615 individuals.

${ }^{\mathrm{e}}$ MarketScan denominators differed according to number of respondents to question.

${ }^{f}$ Northeast: Connecticut, Maine, Massachusetts, New Hampshire, New Jersey, New York, Pennsylvania, Rhode Island, Vermont. Midwest: Illinois, Indiana, lowa, Kansas, Michigan, Minnesota, Missouri, Nebraska, North Dakota, Ohio, South Dakota, and Wisconsin. South: Alabama, Arkansas, Delaware, District of Columbia, Florida, Georgia, Kentucky, Louisiana, Maryland, Mississippi, North Carolina, Oklahoma, South Carolina, Tennessee, Texas Virginia, and West Virginia. West: Alaska, Arizona, California, Colorado, Hawaii, Idaho, Montana, Nevada, New Mexico, Oregon, Utah, Washington, and Wyoming. 171 observations had missing values for regions.

g MarketScan's Midwest region is called "North Central."

${ }^{\mathrm{h}}$ The Medical Expenditure Panel Survey sample excluded part-time employees.

'MarketScan analysis did not identify those with paid sick leave; it used a sample of privately insured individuals.

The opinions expressed by authors contributing to this journal do not necessarily reflect the opinions of the U.S. Department of Health and Human Services, the Public Health Service, the Centers for Disease Control and Prevention, or the authors' affiliated institutions. 
Table 2. Regression-Adjusted Estimates of the Effect of Selected Health Risk Factors or Chronic Diseases on Number of Excess Missed Workdays ${ }^{a}$ per Year per Employee in US Workforce ${ }^{b, c}$

\begin{tabular}{|c|c|c|c|c|c|c|}
\hline \multirow[b]{2}{*}{ Risk Factor or Disease } & \multicolumn{3}{|c|}{ Single Factor or Disease ${ }^{d}$} & \multicolumn{3}{|c|}{ Multiple Factors or Diseases ${ }^{e}$} \\
\hline & No Controls & $\begin{array}{l}\text { Adjusted for Age, } \\
\text { Sex, Race }\end{array}$ & Full Model & Risk Factor & Chronic Disease & All \\
\hline \multicolumn{7}{|c|}{ Medical Expenditure Panel Survey } \\
\hline Current smoking & $0.67(0.35-0.99)$ & $0.76(0.44-1.08)$ & $0.58(0.25-0.92)$ & $0.66(0.59-0.71)$ & NA & $0.26(0.19-0.31)$ \\
\hline Physical inactivity & $0.73(0.45-1.01)$ & $0.64(0.35-0.93)$ & $0.63(0.33-0.92)$ & $0.49(0.44-0.52)$ & NA & $0.50(0.44-0.55)$ \\
\hline Obesity & $1.29(0.98-1.60)$ & $1.12(0.79-1.44)$ & $1.02(0.70-1.33)$ & $0.95(0.90-1.00)$ & $\mathrm{NA}$ & $0.20(0.17-0.26)$ \\
\hline Hypertension & $1.51(1.21-1.82)$ & $1.28(0.97-1.58)$ & $1.13(0.84-1.42)$ & NA & $1.08(1.03-1.12)$ & $0.96(0.90-1.00)$ \\
\hline Diabetes & $1.49(1.09-1.88)$ & $1.17(0.77-1.57)$ & $1.03(0.63-1.42)$ & NA & $0.72(0.63-0.80)$ & $0.62(0.53-0.70)$ \\
\hline \multicolumn{7}{|l|}{ MarketScan } \\
\hline Current smoking & $1.77(1.64-1.90)$ & $1.82(1.69-1.97)$ & $1.07(0.83-1.31)$ & $1.47(0.07-2.2)$ & NA & $1.51(0.77-2.25)$ \\
\hline $\begin{array}{l}\text { Current smoking, controlled } \\
\text { for former smoking }\end{array}$ & $2.41(1.66-3.16)$ & $2.31(1.57-3.05)$ & $2.20(1.45-2.95)$ & $2.21(1.76-2.66)$ & NA & $1.95(1.23-2.74)$ \\
\hline Physical inactivity & $2.23(1.80-2.67)$ & $2.06(1.64-2.49)$ & $1.94(1.51-2.36)$ & $1.70(1.26-2.13)$ & $\mathrm{NA}$ & $1.64(1.20-2.08)$ \\
\hline Obesity & $0.92(0.81-1.02)$ & $0.75(0.66-0.85)$ & $0.59(0.49-0.69)$ & $1.16(0.71-1.6)$ & NA & $0.88(0.42-1.34)$ \\
\hline Hypertension & $2.38(2.20-2.55)$ & $2.06(1.64-2.31)$ & $1.23(1.06-1.41)$ & NA & $0.73(0.52-0.95)$ & $0.85(0.31-1.37)$ \\
\hline Diabetes & $2.29(1.97-2.62)$ & $2.05(1.72-2.38)$ & $1.35(0.98-1.73)$ & NA & $1.17(0.82-1.53)$ & $1.71(0.77-2.65)$ \\
\hline
\end{tabular}

Abbreviations: MEPS, Medical Expenditure Panel Survey; NA, not applicable.

${ }^{a}$ Number of excess missed workdays defined as the difference in the number of days missed from work by those who reported having a risk factor or chronic disease and those who did not.

${ }^{b}$ Data sources: MarketScan and Medical Expenditure Panel Survey [19], 2008-2011. MarketScan is a large US commercial health care claims database; it is a deidentified convenience subpopulation of privately insured individuals (18).

${ }^{c}$ Regression estimates from zero-inflated Poisson regression, robust standard errors clustered by respondent (MarketScan). In addition, MEPS estimates weighted and standard errors adjusted for complex survey design.

${ }^{\mathrm{d}}$ Models for 1 risk factor or chronic disease in regression (specified by the row). The column depicts level of controls where the full model includes controls for age, sex, race (MEPS only), industry, part-time status, union membership, region, and sick-leave policy (MEPS only).

${ }^{\mathrm{e}}$ Models for multiple risk factors or diseases, listed by row (eg, risk factors regression includes smoking, inactivity, and obesity). All regressions include controls for age, sex, race (MEPS only), industry, part-time status, union membership, region, and sick-leave policy (MEPS only). 
Table 3. Annual Cost of Absenteeism Borne by US Employers Because of Selected Health Risk Factors or Chronic Diseases Among Employees ${ }^{a}$

\begin{tabular}{|c|c|c|c|c|c|c|}
\hline & Prevalence, $\%^{b}$ & $\begin{array}{l}\text { No. of People in } \\
\text { US Workforce } \\
\text { With Condition, in } \\
\text { Millions }^{c}\end{array}$ & $\begin{array}{l}\text { No. of Excess Missed } \\
\text { Workdays }{ }^{d} \text { per } \\
\text { Employee per Year }\end{array}$ & $\begin{array}{l}\text { Cost per Employee } \\
\text { per Year, \$ }\end{array}$ & $\begin{array}{l}\text { Total US Cost } \\
\text { per Year, } \\
\text { Billions, } \$ g\end{array}$ & $\begin{array}{l}\text { US Cost Scenario } \\
\text { Lower-Upper, } \\
\text { Billions, } \$\end{array}$ \\
\hline Risk Factor or Disease & $A$ & $B$ & $c$ & $D$ & $E$ & $F$ \\
\hline Current smoking & 17.0 & 23.6 & 0.58 & 153 & 3.6 & $1.6-5.9$ \\
\hline Physical inactivity & 39.7 & 55.2 & 0.63 & 166 & 9.1 & $3.9-14.6$ \\
\hline Obesity & 30.0 & 41.6 & 1.02 & 269 & 11.2 & $4.8-17.9$ \\
\hline Hypertension & 24.9 & 34.6 & 1.13 & 298 & 10.3 & $4.4-16.5$ \\
\hline Diabetes & 6.0 & 8.3 & 1.03 & 272 & 2.2 & $0.9-3.5$ \\
\hline
\end{tabular}

Abbreviation: MEPS, Medical Panel Expenditure Survey.

a Data sources: MarketScan and Medical Expenditure Panel Survey [19], 2008-2011. MarketScan is a large US commercial health care claims database; it is a deidentified convenience subpopulation of privately insured individuals (18).

${ }^{\mathrm{b}}$ Prevalence estimate from MEPS data $(A)$.

${ }^{\mathrm{c}}$ Assumes workforce population of 139 million people: $B=A \times 139$ million.

${ }^{d}$ Number of excess missed workdays defined as the difference in the number of days missed from work by those who reported having a risk factor or chronic disease and those who did not.

${ }^{\mathrm{e}} \mathrm{C}=$ MEPS regression estimates for single factor or disease, full model (Table 2).

${ }^{f}$ Assumes an average employment cost of $\$ 33.00$ per hour and an 8-hour work day (in 2015 dollars): $D=C \times 8 \times 33$.

${ }^{g}$ Total cost $(E)=B \times D$ in 2015 dollars.

${ }^{\mathrm{h}}$ Lower and upper cost scenarios based on multipliers of 0.43 and 1.6 respectively: lower value $=0.43 \times E$; upper value $=1.6 \times E$. 
Table 4. Annual Total Absenteeism and Costs to Employers in the United States Because of Selected Health Risk Factors or Chronic Diseases Among Employees, by Size of Employer ${ }^{a}$

\begin{tabular}{|c|c|c|c|c|c|}
\hline Condition & Prevalence, \% & $\begin{array}{l}\text { No. of Excess } \\
\text { Missed Workdays } \\
\text { per Employee }\end{array}$ & $\begin{array}{l}\text { Total No. of Missed } \\
\text { Workdays per Year } \\
\text { per Employer }\end{array}$ & $\begin{array}{l}\text { Total Cost per } \\
\text { Year, } \$^{\mathrm{C}}\end{array}$ & Cost per Employee per Year, \\
\hline \multicolumn{6}{|c|}{ Small firm (100 employees) ${ }^{d}$} \\
\hline Current smoking & 17 & 0.58 & 10 & 2,603 & 26 \\
\hline Physical inactivity & 40 & 0.63 & 25 & 6,603 & 66 \\
\hline Obesity & 30 & 1.02 & 31 & 8,065 & 81 \\
\hline Hypertension & 25 & 1.13 & 28 & 7,419 & 74 \\
\hline Diabetes & 6 & 1.03 & 6 & 1,621 & 16 \\
\hline \multicolumn{6}{|c|}{ Large employer (1,000 employees) $^{e}$} \\
\hline Current smoking & 27 & 1.07 & 292 & 77,117 & 77 \\
\hline Physical inactivity & 56 & 1.94 & 1,083 & 285,785 & 286 \\
\hline Obesity & 26 & 0.59 & 153 & 40,498 & 40 \\
\hline Hypertension & 18 & 1.23 & 221 & 58,450 & 58 \\
\hline Diabetes & 5 & 1.35 & 65 & 17,107 & 17 \\
\hline
\end{tabular}

${ }^{a}$ Data sources: MarketScan and Medical Expenditure Panel Survey (19), 2008-2011. MarketScan is a large US commercial health care claims database; it is a deidentified convenience subpopulation of privately insured individuals (18).

${ }^{\mathrm{b}}$ Number of excess missed workdays defined as the difference in the number of days missed from work by those who reported having a risk factor or chronic disease and those who did not.

${ }^{c}$ Based on average employment cost of $\$ 33.00$ per hour and an 8-hour workday. All costs are in 2015 dollars.

${ }^{d}$ Small employer costs based on Medical Expenditure Panel Survey prevalence and estimated absenteeism.

${ }^{\mathrm{e}}$ Large employer costs based on MarketScan prevalence and estimated absenteeism. 